\title{
Effect of Partial Dietary Substitution of Meat Meal for Fish Meal on the Growth and Body Composition of the Juvenile Olive Flounder Paralichthys olivaceus
}

\author{
Sung Hwoan Cho ${ }^{1}$, Sang-Mok Lee ${ }^{1}$, Bum-Hee Park $^{1}$, In-Seok Park ${ }^{1}$, \\ Cheol Young Choi ${ }^{1}$, Sang-Min Lee ${ }^{2}$, Byung Hee Min ${ }^{3}$, \\ Sung-Bum Hur ${ }^{3}$ and Young Soo Lim $^{4}$ \\ ${ }^{1}$ Division of Marine Environment and BioScience, College of Ocean Science and \\ Technology, Korea Maritime University, Busan 606-791, Korea \\ ${ }^{2}$ Faculty of Marine Biosicence and Technology, Kangnung National University \\ Gangnung 210-702, Korea \\ ${ }^{3}$ Department of Aquaculture, Pukong National University, Busan 608-739, Korea \\ ${ }^{4}$ Aquacultue Environment Institute, National Fisheries Research \& Development Institute, \\ Tongyoung 650-943, Korea
}

\begin{abstract}
This study was conducted to investigate the effect of partially substituting meat meal for fish meal on the growth and body composition of juvenile olive flounder Paralichthys olivaceus during the winter season. Twenty-five fish (initial body weight, $23 \mathrm{~g}$ ) were distributed into twelve $250 \mathrm{~L}$ flow-through tanks. Four experimental diets were prepared in triplicate: the control, MM20, MM40, and MM60 diets. Sixty percent mackerel meal was used as the primary protein source in the control diet. Meat meal was substituted for 20,40 , and $60 \%$ of the mackerel meal in the MM20, MM40, and MM60 diets, respectively. Survival was not significantly affected by the experimental diets. However, the weight gain and specific growth rate of fish fed the control, MM20, and MM40 diets were significantly higher than those of fish fed the MM60 diet $(\mathrm{P}<0.05)$. The feed efficiency ratio of fish fed the control, MM20, and MM40 diets was significantly higher than that of fish fed the MM60 diet $(\mathrm{P}<0.05)$. The protein efficiency ratio for fish fed the control diet was significantly higher than that for fish fed the MM40 and MM60 diets $(\mathrm{P}<0.05)$. Moisture, crude protein, crude lipid, and ash content, and blood chemistry of the flounder at the end of the feeding trial were unaffected by the experimental diets. Considering these results, it can be concluded that up to $40 \%$ substitution of meat meal for fish meal in the diet could be implemented without a reduction in growth or deterioration of the feed efficiency of juvenile olive flounder during the winter season.
\end{abstract}

Key words: Fish meal, Meat meal, Olive flounder, Paralichthys olivaceus, Dietary substitution

\section{Introduction}

The olive flounder, Paralichthys olivaceus is the most commercially important marine fish for aquaculture in Korea due to both its high annual production and value over the past two decades (KNSO, 2003).

Fish meal is widely used as the main protein source for fish feed because it contains nutrients essential for fish, including amino and fatty acids, and minerals. However, due to overfishing of species (e.g., mackerel and sardines) used in fish meal, a reduction in the availability of these fish, and a high demand for fish meal resulting from the expansion of fish aquaculture,

\footnotetext{
*Corresponding author: chosunh@hhu.ac.kr
}

the price of fish meal has increased sharply. Therefore, many studies have been conducted to find substitute protein sources for olive flounder aquaculture (Kikuchi et al., 1994a, b, c, 1997; Sato and Kikuchi, 1997; Cho et al., 2005).

Sato and Kikuchi (1997) reported that $60 \%$ of whitefish meal could be replaced with meat meal in the diet of juvenile olive flounder (initial body weight: $3 \mathrm{~g}$ ) at $20^{\circ} \mathrm{C}$. Substituting meat meal for fish meal in the diet has been reported to yield superior results in the cultivation of some marine fish (Shimeno et al., 1993a, c; Lee, 2002; Millamena, 2002).

Because water temperature affects the availability of dietary nutrients for fish, the effect of substituting 
meat meal for fish meal in the diet on fish performance could differ according to temperature. Therefore, in this study, the effect of partially substituting meat meal for fish meal on the growth and body composition of juvenile olive flounder Paralichthys olivaceus was examined during the winter season.

\section{Materials and Methods \\ Experimental fish}

Juvenile flounder were purchased from a private flounder hatchery (Kyungbook, Korea) and transported to the lab. Twenty-five fish (initial body weight: $23.0 \pm 0.08 \mathrm{~g}$ ) were distributed into twelve $250 \mathrm{~L}$ flow-through tanks (water volume: $150 \mathrm{~L}$ ) and allowed to acclimate to experimental conditions for one week. During the acclimation period, fish were hand-fed twice daily with commercial feed containing 52\% crude protein and $8 \%$ crude lipid (Jeil Feed Co., Taejeon, Korea).

\section{Preparation of the experimental diets}

Four experimental diets were prepared in triplicate for this study: the control, MM20, MM40, and MM60 diets. Mackerel meal at the level of $60 \%$ was used as the primary protein source in the control diet. Meat meal was substituted for 20,40 , and $60 \%$ of the mackerel meal in the MM20, MM40, and MM60 diets, respectively (Table 1 ). The amino acid compositions of the ingredients used in the experimental diets are given in Table 2. The contents of lysine (Lys) and methionine + cystine (Met + Cys) in meat meal was relatively low compared to that in mackerel meal, but the amount of leucine (Leu) in the meat meal was relatively high. Wheat flour and $\alpha$-starch, and squid liver oil were used as the primary carbohydrate, and lipid sources in the experimental diets, respectively. The ingredients in the experimental diets were mixed well with water at the ratio of 7:3 and pelletized using a pellet-extruder. The experimental diets were dried overnight and stored at $-20^{\circ} \mathrm{C}$ until use.

\section{Experimental conditions}

Sand-filtered seawater was supplied to each experimental tank, and the flow rate of water into each tank was $6.6 \mathrm{~L} / \mathrm{min}$. Fish were hand-fed to apparent satiation twice daily (09:00 and 17:00 h) throughout the feeding trial. The water temperature ranged from 9.5 to $16.0^{\circ} \mathrm{C}\left(\right.$ mean $\left.\pm \mathrm{SD}: 12.3 \pm 1.75^{\circ} \mathrm{C}\right)$ throughout the feeding trial, and the photoperiod followed natural conditions. The feeding trial continued for 10 weeks.

\section{Analysis of chemical composition and blood chemistry of fish}

At the beginning and end of the experiment, ten fish
Table 1. Ingredients and proximate analysis of the experimental diets

\begin{tabular}{lcccc}
\hline & \multicolumn{4}{c}{ Diets } \\
\cline { 2 - 5 } & Control & MM20 & MM40 & MM60 \\
\hline Ingredients Mackerel meal $^{1}$ & 60 & 48 & 36 & 24 \\
Meat meal $^{2}$ & & 15 & 30 & 45 \\
Wheat flour $^{\text {a }}$ & 26.8 & 24 & 21.2 & 18.4 \\
-starch $^{3}$ & 5 & 5 & 5 & 5 \\
Brewer yeast $_{\text {Squid liver oil }}$ & 2 & 2 & 2 & 2 \\
Vitamin premix $^{4}$ & 2 & 1.8 & 1.6 & 1.4 \\
Mineral premix & 2 & 2 & 2 & 2 \\
Choline (50\%) & 2 & 2 & 2 & 2 \\
& 0.2 & 0.2 & 0.2 & 0.2 \\
Nutrients (\%) & & & & \\
Crude protein & 48.7 & 50.4 & 51.7 & 54.3 \\
Crude lipid & 7.5 & 7.0 & 7.4 & 7.9 \\
Ash & 9.2 & 9.4 & 9.8 & 10.4 \\
\hline
\end{tabular}

${ }^{1}$ Produced by steam dry method, imported from Chile. ${ }^{2}$ Provided by Shinchon Feed Co. Ltd., Incheon, Korea. ${ }^{3}$ Sigma Chemical, St. Louis, MO, USA. ${ }^{4}$ Vitamin premix contained the following amount that were diluted in cellulose ( $\mathrm{g} / \mathrm{kg}$ mix): L-ascorbic acid, 121.2; DL- $\alpha$-tocopheryl acetate, 18.8 ; thiamin hydrochloride, 2.7; riboflavin, 9.1; pyridoxine hydrochloride, 1.8; niacin, 36.4; Ca-D-pantothenate, 12.7; myo-inositol, 181.8; D-biotin, 0.27 ; folic acid, 0.68; p-aminobenzoic acid, 18.2; menadione, 1.8; retinyl acetate, 0.73; cholecalciferol, 0.003; cyanocobalamin, 0.003 . ${ }^{5}$ Mineral premix contained the following ingredients $(\mathrm{g} / \mathrm{kg}$ mix): $\mathrm{MgSO}_{4} \cdot 7 \mathrm{H}_{2} \mathrm{O}, 80.0 ; \mathrm{NaH}_{2} \mathrm{PO}_{4} \cdot 2 \mathrm{H}_{2} \mathrm{O}, 370.0 ; \mathrm{KCl}$, 130.0; ferric citrate, $40.0 ; \mathrm{ZnSO}_{4} \cdot 7 \mathrm{H}_{2} \mathrm{O}, 20.0$; Calactate, 356.5; $\mathrm{CuCl}_{2}, 0.2 ; \mathrm{AlCl}_{3} \cdot 6 \mathrm{H}_{2} \mathrm{O}, 0.15 ; \mathrm{KI}, 0.15$; $\mathrm{Na}_{2} \mathrm{Se}_{2} \mathrm{O}_{3}, 0.01 ; \mathrm{MnSO}_{4} \cdot \mathrm{H}_{2} \mathrm{O}, 2.0 ; \mathrm{CoCl}_{2} \cdot 6 \mathrm{H}_{2} \mathrm{O}, 1.0$.

Table 2. Proximate analysis and essential amino acid compositions of the ingredients

\begin{tabular}{|c|c|c|c|c|}
\hline & \multicolumn{4}{|c|}{ Protein sources } \\
\hline & Mackerel $^{1}$ & $\begin{array}{l}\text { Meat } \\
\text { meal }^{2}\end{array}$ & $\begin{array}{c}\text { Wheat } \\
\text { flour }\end{array}$ & $\begin{array}{c}\text { Brewer's } \\
\text { yeast }\end{array}$ \\
\hline \multicolumn{5}{|c|}{ Proximate composition ( $\%$ of DM basis) } \\
\hline Moisture & 8.7 & 5.0 & 10.5 & 3.6 \\
\hline Crude rotein & 75.3 & 74.4 & 11.7 & 48.7 \\
\hline Crude lipid & 7.9 & 10.8 & 1.0 & 2.0 \\
\hline Ash & 15.7 & 13.2 & 1.0 & 9.1 \\
\hline \multicolumn{5}{|c|}{ Essential amino acids (\% in protein) } \\
\hline Arg & 6.7 & 5.7 & 6.5 & 6.2 \\
\hline His & 4.0 & 3.2 & 4.1 & 3.6 \\
\hline Ile & 4.0 & 4.0 & 3.9 & 4.0 \\
\hline Leu & 8.2 & 10.1 & 8.6 & 9.2 \\
\hline Lys & 8.4 & 6.1 & 7.1 & 7.4 \\
\hline Met+Cys & 3.0 & 1.8 & 1.6 & 1.6 \\
\hline Phe+Tyr & 7.3 & 7.6 & 7.6 & 7.9 \\
\hline Thr & 5.1 & 4.7 & 4.7 & 4.9 \\
\hline Val & 5.6 & 5.7 & 5.6 & 5.5 \\
\hline Total & 52.3 & 48.9 & 49.7 & 50.3 \\
\hline
\end{tabular}

${ }^{1}$ Produced by steam dry method, imported from Chile.

${ }^{2}$ Provided by Shinchon meat meal Ind. Co., Incheon, Korea. 
were sampled and sacrificed for proximate analysis. Crude protein content was determined by the Kjeldahl method using the Auto Kjeldahl System (Buchi B324/435/412; Buchi, Flawil, Switzerland); lipid content was assessed by the ether-extraction method; moisture content was measured by oven (drying at $105^{\circ} \mathrm{C}$ for $24 \mathrm{~h}$ ); fiber content was calculated with an automatic analyzer (Fibertec, Tecator, Sweden); ash content was determined using a muffle furnace $\left(550^{\circ} \mathrm{C}\right.$ for $4 \mathrm{~h}$ ) based on standard methods (AOAC, 1990). Blood samples were obtained from the caudal vein of five fish from each tank by using a heparinized syringe after they were starved for $24 \mathrm{~h}$ and anesthetized with MS-222 at a concentration of $100 \mathrm{ppm}$ at the end of the feeding trial. Plasma was collected after centrifugation (3000 rpm for $10 \mathrm{~min}$ ) and stored at $-70^{\circ} \mathrm{C}$ as separate aliquots for analysis of protein, glucose and glutamic oxaloacetic transaminase (GOT)

\section{Statistical analysis}

One-way ANOVA and Duncan's multiple range test (Duncan, 1955) were used to analyze the significance of the difference among the means of treatments by using SAS Version 9.1 (SAS Institute, Cary, NC, USA).

\section{Results and Discussion}

Survival, weight gain (g/fish), and specific growth rate (SGR) of olive flounder fed the experimental diets for 10 weeks during the winter season are given in Table 3. Survival was not significantly $(\mathrm{P}>0.05)$ affected by the experimental diets. Similarly, the survival of flounder was not affected by different substitution ratios of meat meal for fish meal in the experimental diets (Sato and Kikuchi, 1997).

However, weight gain and SGR of fish fed the control, MM20, and MM40 diets were significantly $(\mathrm{P}<0.05)$ higher than those of fish fed the MM60 diet in this study, indicating that the growth of juvenile olive flounder fed the diet in which meat meal was substituted for fish meal at levels up to $40 \%$ was comparable to that of fish fed the fish meal-based diet during the winter season. However, Sato and Kikuchi
(1997) reported that $60 \%$ fish meal could be replaced by meat meal in the diet of juvenile olive flounder at $20^{\circ} \mathrm{C}$. This difference in results may be attributable to differences in water temperature; the mean water temperature in our study was $12.3^{\circ} \mathrm{C}$. The lower metabolism rate of fish at this temperature may have been a factor. Differences in the protein content of the control diet in the two studies could have been another reason. The protein level of the control diet used in Sato and Kikuchi's (1997) study was 55.6\% compared to $48.7 \%$ in our study. Shimeno et al. (1993a) found that the growth of yellowtail fed diets in which meat meal was substituted for fish meal at levels of up to about $40 \%$ was comparable to that of fish fed the fish meal-based diet. Growth of juvenile flounder fed diets in which meat and bone meal were substituted for fish meal at levels up to $20 \%$ was comparable to that of fish fed the fish meal-based diet (Kikuchi et al., 1997).

The amount of feed consumed (g/fish), feed efficiency ratio (FER), and protein efficiency ratio (PER) of olive flounder fed the experimental diets during the winter season are presented in Table 4. Feed consumption was not significantly affected by the experimental diets $(\mathrm{P}>0.05)$. However, the FER of flounder fed the control, MM20, and MM40 diets was significantly $(\mathrm{P}<0.05)$ higher than that of fish fed the MM60 diet. Similarly, the FER of yellowtail and olive flounder fed diets in which up to $40 \%$ meat meal was substituted for fish mea was comparable to that of fish fed a fish meal-based diet (Shimeno et al., 1993a; Sato and Kikuchi, 1997).

The PER for olive flounder fed the control diet was not significantly different from that for fish fed the MM20 diet, but was significantly higher than that for fish fed the MM40 and MM60 diets in this study. In the present study, the poorest PER was obtained in flounder fed the MM60 diet, PER decreased linearly fish meal by meat meal in the diets of yellowtail (Shimeno et al., 1993a).

Moisture, crude protein, crude lipid, and ash content of the whole flounder ranged from 74.1 to $74.9 \%, 17.4$ to $17.9 \%, 3.1$ to $3.3 \%$, and 2.6 to $3.9 \%$, respectively, with an increase in the substitution ratio of fish meal

Table 3. Survival, weight gain, specific growth rate (SGR) of juvenile olive flounder fed the experimental diets substituting meat meal for fish meal for 10 weeks during the winter season (mean \pm S.E.)

\begin{tabular}{lccccc}
\hline Diets & Initial weight (g/fish) & Final weight $(\mathrm{g} /$ fish $)$ & Survival $(\%)$ & Weight gain $(\mathrm{g} /$ /ish) & SGR \\
\hline Control & $23.1 \pm 0.05$ & $56.1 \pm 2.75^{\mathrm{a}}$ & $96.0 \pm 2.31^{\text {n.s. }}$ & $33.0 \pm 2.70^{\mathrm{a}}$ & $1.25 \pm 0.065^{\mathrm{a}}$ \\
MM20 & $23.2 \pm 0.06$ & $55.6 \pm 1.74^{\mathrm{a}}$ & $94.7 \pm 2.67$ & $32.5 \pm 1.67^{\mathrm{a}}$ & $1.23 \pm 0.039^{\mathrm{a}}$ \\
MM40 & $22.9 \pm 0.14$ & $52.3 \pm 1.31^{\mathrm{a}}$ & $97.3 \pm 1.33$ & $29.3 \pm 1.15^{\mathrm{a}}$ & $1^{\mathrm{a}} 16 \pm 0.025^{\mathrm{a}}$ \\
MM60 & $23.0 \pm 0.09$ & $44.1 \pm 1.13^{\mathrm{b}}$ & $97.3 \pm 2.67$ & $21.1 \pm 1.14^{\mathrm{b}}$ & $0.91 \pm 0.037^{\mathrm{b}}$ \\
\hline
\end{tabular}

Different superscript letters within same columns are significantly different $(\mathrm{P}<0.05)$. n.s.: not significantly different $(P>0.05) .{ }^{1} S G R=(L n$ final weight-Ln initial weight $) \times 100 /$ days of feeding. 
Table 4. Amount of feed supply (g/fish), feed efficiency ratio (FER) and protein efficiency ratio (PER) for juvenile olive flounder fed the experimental diets substituting meat meal for fish meal for 10 weeks during the winter season (mean \pm S.E.)

\begin{tabular}{lccc} 
Diets & $\begin{array}{c}\text { Amount of } \\
\text { feed supply }\end{array}$ & FER $^{1}$ & PER $^{2}$ \\
\hline Control & $36.2 \pm 1.42^{\text {n.s. }}$ & $0.93 \pm 0.053^{\mathrm{a}}$ & $1.91 \pm 0.108^{\mathrm{a}}$ \\
MM20 & $36.5 \pm 0.98$ & $0.91 \pm 0.027^{\mathrm{a}}$ & $1.81 \pm 0.054^{\mathrm{ab}}$ \\
MM40 & $34.5 \pm 1.71$ & $0.87 \pm 0.003^{\mathrm{a}}$ & $1.68 \pm 0.005^{\mathrm{b}}$ \\
MM60 & $33.3 \pm 0.10$ & $0.65 \pm 0.028^{\mathrm{b}}$ & $1.19 \pm 0.052^{\mathrm{c}}$ \\
\hline
\end{tabular}

Different superscript letters within same columns are significantly different $(\mathrm{P}<0.05)$. n.s.: not significantly different $(P>0.05)$. ${ }^{1}$ FER=weight gain/dry feed fed. ${ }^{2} \mathrm{PER}=$ weight gain/protein fed.

by meat meal. Similarly, in a previous study, PER deteriorated with an increase in substitution ratio of and was not significantly affected by the experimental diets $(\mathrm{P}>0.05)$. Similarly, body composition was not affected by substitution of other protein sources for fish meal diets of yellowtail and flounder in other studies (Shimeno et al., 1993a, b; Kikuchi, 1999; Cho et al., 2005). However, unlike in this study, the chemical composition of fish was directly influenced by dietary nutrient composition in many other studies (Shimeno et al., 1992; Kikuchi et al., 1994a, b, 1997; Sato and Kikuchi, 1997).

Plasma protein, glucose, and glutamic oxaloacetic transaminase (GOT) of olive flounder ranged from 3.6 to $5.1 \mathrm{~g} / \mathrm{dL}, 17.0$ to $23.2 \mathrm{mg} / \mathrm{dL}$, and 16.8 to $24.4 \mathrm{IU} / \mathrm{L}$, respectively, and were not significantly affected by the experimental diets in this study $(\mathrm{P}>0.05)$. Similarly, the blood chemistry of yellowtail and olive flounder was not influenced by diets in which other protein sources were substituted for fish meal (Shimeno et al., 1993a, c; Kikuchi et al., 1994b; Kikuchi et al., 1997; Sato and Kikuchi, 1997). However, the substitution of defatted soybean meal and feather meal for fish meal was shown to affect the blood chemistry of olive flounder (Kikuchi et al., 1994a; Kikuchi, 1999).

Considering these results, it can be concluded that meat meal can be substituted for fish meal at levels of up to $40 \%$ without a reduction in growth or deterioration of feed efficiency of juvenile olive flounder during the winter season.

\section{Acknowledgements}

This work was supported by the funds of the Ministry of Marine Affairs in Korea.

\section{References}

AOAC (Association of Official Analytical Chemists). 1990.
Official Methods of Analysis. 15th edition. Association of Official Analytical Chemists. Arlington, USA. pp. 1298.

Cho, S.H., S. Lee, S. Lee, B. Park, I. Park, C. Y. Choi, B.H. Min, S. Hur and J. Jo. 2005. Effect of partial replacement of fish meal with squid liver meal ${ }^{\mathrm{TM}}$ in the diet on growth and body composition of juvenile olive flounder (Paralichthys livaceus) during winter season. J. Fish. Sci. Technol., 8, 65-69.

Duncan, D.B. 1955. Multiple range and multiple $F$ tests. Biometrics, 11, 1-42.

Kikuchi, K., T. Furuta and H. Honda. 1994a. Utilization of feather meal as a protein source in the diet of juvenile flounder. Fish. Sci., 60, 203-206.

Kikuchi, K., T. Furuta and H. Honda. 1994b. Utilization of soybean meal as a protein source in the diet of juvenile flounder, Paralichthys olivaceus. Suisanzoshoku, 42, 601-604.

Kikuchi, K., T. Sato, T. Furuuta, I. Sakaguchi and Y. Deguchi. 1997. Use of meat and bone meal as protein source in the diet of juvenile Japanese flounder. Fish. Sci., 63, 29-32.

KNSO (Korea National Statistical Office). 2003. KOSIS Statistical DB, Daejeon, Korea.

Lee, S.M. 2002. Apparent digestibility coefficients of various feed ingredients for juvenile and grower rockfish (Sebastes schlegeli). Aquaculture, 207, 79-95.

Millamena, O.M. 2002. Replacement of fish meal by animal by-product meals in a practical diet for grow-out culture of grouper Epinephelus coioides. Aquaculture, 204, 75-84.

Sato, T. and K. Kikuchi. 1997. Meatmeal as a protein source in the diet of juvenile Japanese flounder. Fish. Sci., 63, 877-880.

Shimeno, S., H. Hosokawa, M. Kumon, T. Masumoto and M. Ukawa. 1992. Inclusion of defatted soybean meal diet for fingerling yellowtail. Nippon Suisan Gakkaishi, 58, 1319-1325.

Shimeno, S., T. Masumoto, T. Hujita, T. Mima and S. Ueno. 1993a. Alternative protein sources for fish meal in diets of young yellowtail. Nippon Suisan Gakkaishi, 59, 137-143.

Shimeno, S., H. Hosokawa, M. Kumon, H. Ando and M. Ukawa. 1993b. The growth performance and body composition of young yellowtail fed with diets containing defatted soybean meal for a long time period. Nippon Suisan Gakkaishi, 59, 821-825.

Shimeno, S., T. Mima, T. Imanaga and K. Tomaru. 1993c. Inclusion of combination of defatted soybean meal, meat meal, and corn gluten meal to yellowtail diets. Nippon Suisan Gakkaishi, 59, 1889-1895.

(Received September 2005, Accepted August 2005) 